\title{
Leitura e suas metáforas alimentares
}

\section{Reading and its alimentary metaphors}

https://doi.org/10.34112/2317-0972a2016v34n66p61-74

\section{Olga Donata Guerizoli Kempinska ${ }^{1}$}

Resumo: A popularização da leitura solitária e silenciosa a partir do século XVIII foi acompanhada da exclusão do corpo, tão presente na prática da leitura pública e em voz alta. Frente à insistência na imobilidade e na interiorização abstrata como elementos principais do ato de ler, as metáforas alimentares da leitura rapidamente desmentiram a ausência das atividades corporais e até mesmo viscerais do leitor. Este trabalho procura investigar as reverberações semânticas das metáforas alimentares, sobretudo naquilo que tange à subversão da atividade puramente espiritual da leitura e ao levantamento, a partir de uma perspectiva mais acolhedora com relação ao corpo, de problemas teóricos da recepção estética. PALAVRAS-chaVE: Leitura; corpo; estética da recepção; distância estética.

ABSTRACT: The popularization of the practice of reading as a solitary and silent act since the 18th century had as its result the elimination of the body experience manifested in public and oral reading. In response to this emphasis on immobility and the abstract assimilation as main features of the act of reading, the alimentary metaphors quickly subverted the absence of reader's corporal and visceral activities. This paper investigates some of the semantic reverberations of the alimentary metaphors of reading, especially those in touch

1. Universidade Federal Fluminense, Niterói, RJ, Brasil. 
with the subversion of the reader's activity as purely spiritual, and with the questioning, from a point of view receptive to the body relations, of some aesthetic notions.

KEYWORDS: Reading; body; reader-response theory; esthetic distance.

Leio para viver. Li muito cedo: não comia, lia.

Hélène Cixous

"Leitores vorazes" que "devoram" livros, que os "saboreiam" ou até mesmo com eles "se deliciam": essas e tantas outras expressões, ao transporem atividades espirituais em termos corporais, estabelecem uma irresistível e, no entanto, raramente explicitada analogia entre "ler" e "comer". Essa comparação aparentemente irreverente, na qual as metáforas alimentares aproximam a leitura do ato de absorver, degustar e digerir alimentos, revela-se instigante, na medida em que permite o deslocamento de algumas noções teóricas da estética da recepção. Seu caráter intrigante afirma-se, com efeito, não apenas por meio do rebaixamento da atividade supostamente intelectual, espiritual e elevada a um gesto de assimilação prazerosa bruta, mas também no levantamento, a partir de uma perspectiva mais acolhedora com relação ao corpo, de questões relativas ao gosto e à forma.

Dividido em três partes, meu trabalho procura contemplar diversas reverberações semânticas das metáforas alimentares da leitura e suas possíveis consequências teóricas. Em primeiro lugar, debruço-me sobre o problema da identificação manifesto no ato de ler e explicitado por meio de sua comparação com a absorção de alimentos. Na segunda parte, procuro mostrar que, por meio da tematização das sensações do paladar, a literatura, que enquanto atividade de leitura é, contudo, uma experiência eminentemente visual, procura participar da subversão da hierarquia dos sentidos estéticos tradicionalmente valorizados. Na terceira e última parte, insisto na importância das metáforas alimentares naquelas teorias contemporâneas da leitura que recorrem à comparação entre texto e corpo.

\section{A leitura e a identificaÇão}

O garçom protagonista do hilário romance de Bohumil Hrabal Eu servi o Rei da Inglaterra relata como os clientes que entravam no restaurante literalmente espelhavam em sua aparência seus respectivos costumes alimentares, o que, por sua vez, tornava possível adivinhar que pratos iam encomendar. Assim, ao olho esperto do 
maître daquele restaurante praguense dos anos 30 era possível avaliar a relação íntima e secreta entre uma pessoa e sua comida e dizer de antemão seu pedido, como, por exemplo, "Chá e torrada frita sem alho", deduzido a partir da tez reveladora de "um problema de vesícula biliar" (HRABAL, 2002, p. 91). Baseado nesse mimetismo engraçado que envolvia não apenas o tipo de roupa usada, mas também o porte, os gestos, a expressão facial e até mesmo eventuais problemas de saúde refletidos na pele, existia entre garçons um jogo de adivinhar o que um cliente ia pedir. Humor do escritor tcheco à parte, de uma certa maneira, o que e, sobretudo, como uma pessoa come revela quem ela é. E é tentador pensarmos que, tal como os gostos alimentares deixam numerosos traços na aparência de cada um, as preferências pelos livros também dizem algo importante a respeito de seu caráter e de suas formas de vida.

É verdade que, ao contrário da comida, que, correspondendo a uma necessidade biológica, é um imperativo, a prática da leitura é uma escolha, dentro da qual se operam ainda outras escolhas afetivas. Nesse sentido, se uma pessoa lê, o que ela lê literatura de consumo, clássica ou exigente - e, mais ainda, como lê - ora rapidamente devorando, ora beliscando sem terminar, ora saboreando demoradamente -, em certa medida revela algo sobre seu modo de viver e de pensar. Há pratos indigestos como há livros indigestos. Há também comidas da nossa infância, incomparáveis, pois inaugurais das nossas experiências prazerosas e inseparáveis do nosso gosto pela vida. Análogos a essas, existem livros inigualáveis lidos por ou para nós nos inícios da nossa vida, que, tal como alguns dos pratos antigamente preparados pelas avós, nos abriram aos prazeres da palavra e da imaginação. Existem livros nos quais como adolescentes procurávamos pelos segredos do sexo, comparáveis a festas nas quais experimentávamos bebidas alcoólicas. A comparação entre leitura e comida não se limita, aliás, à analogia entre duas práticas, mas revela também algo a respeito da própria natureza do estético como um acréscimo subjetivo: como a nossa fome e a nossa disposição são às vezes capazes de transformar um prato muito simples em um delicioso festim, também conseguimos fazer leituras excepcionais e muito criativas de livros banais.

Historicamente, a intensificação do uso das metáforas alimentares da leitura parece ter coincidido no Ocidente com "a revolução da leitura no final do século XVIII” (WITTMANN, 2001, p. 355). Foi então que, com o crescimento da classe burguesa, aumentou também subitamente a prática da leitura, antes de mais nada, de romances. Naquela época floresceu, de fato, tanto a leitura extensiva, que busca sempre por novos livros, novos saberes e experiências, quanto a intensiva, que, ao 
contrário, procura exacerbar a intensidade emocional da experiência subjetiva. Se, por um lado, através da popularização crescente da prática da leitura silenciosa e solitária, o corpo do leitor se viu cada vez mais excluído da experiência leitora, por outro, de maneira um tanto insidiosa, a leitura passou a ser percebida cada vez mais como uma alternativa suspeita a atividades físicas e fisiológicas. Foi justamente a partir do final do século XVIII, no bojo das associações da leitura "à ociosidade, ao consumo de drogas e ao autoerotismo" (PETIT, 2013, p. 102), que surgiram muitas comparações, sobretudo depreciativas, entre o ato de comer e o ato de ler. Assim, por exemplo, um observador crítico dos leitores alemães da época comparou diretamente a leitura aos vícios, sobretudo orais:

Mal devoraram a última página de um livro e já estão olhando em volta à procura de um novo [...]. Nenhum fumante, nenhuma bebedora de café, nenhum bebedor de vinho, nenhum jogador se apega tanto a seu cachimbo, a sua xícara, a sua garrafa e a sua mesa de jogo quanto aquela gente sedenta de leitura se apega a seus livros. (WITTMANN, 2001, p. 355)

Na mesma época, uma outra observadora censurava também a quantidade de leituras, lançando mão de uma metáfora alimentar particularmente evocativa, sobretudo pelo fato de mobilizar uma imagem animal: "Aqui empanturra-se as pessoas com leituras como se empanturra gansos com massa" (WITTMANN, 2001, p. 373).

Mesmo que com o tempo as metáforas alimentares da leitura tenham se tornado mais ambivalentes, é interessante notarmos que seu primeiro sentido parece ter sido, sobretudo, negativo. Elas serviram à censura da quantidade e também da qualidade de leituras, revelando, antes de mais nada, seus excessos. Com isso, as metáforas alimentares da leitura subvertiam também as pretensões espirituais da atividade de ler, denunciando a presença tácita do corpo e das emoções viscerais em meio a uma atividade aparentemente espiritual.

Nesse sentido, até mesmo nos dias de hoje a metáfora mais amplamente utilizada parece ser a de "literatura de consumo". Essa expressão bastante depreciativa mantém, de fato, uma analogia inegável com a prática e a circulação do fast-food: fácil, feita de maneira industrializada, barata e de má qualidade nutricional. Além disso, sua variedade é apenas aparente, tratando-se, na realidade, de uma repetição da mesmice. Ademais de transpor algo a respeito de sua divulgação, leitura e construção, a expressão "literatura de consumo" chega também a contemplar o próprio processo de interpretação, pois “consumir” pressupõe um ato de gastar até o fim, 
de esgotar, tal como se esgota o sentido de um livro baseado no estereótipo em uma única leitura. Nada sobra, no que diz respeito a eventuais restos do sentido, a dúvidas quanto a interpretação, pois se trata aqui de uma absorção una, única e unívoca. No âmbito da estética da recepção, Wolfgang Iser que, como veremos, utiliza metáforas alimentares sobretudo em sua acepção negativa, assinala essa saciedade do sentido na literatura de consumo:

O leitor ideal deveria então não apenas apreender o potencial do sentido de um texto independentemente das determinações históricas de sua própria situação, mas também efetuar seu acabamento. Isso feito, o texto ficaria esgotado em um tal ato: uma perniciosa idealidade para a literatura, sem dúvida. Existem, contudo, textos destinados justamente a isso, como nos mostra a própria abundância da literatura fácil e de consumo. (ISER, 1984, p. 54)

Reveladoras especialmente de componentes somáticos do ato da leitura, as metáforas alimentares encontraram uma acolhida criativa em meio à investigação do processo da recepção a partir do ponto de vista da psicanálise. Assim, por exemplo, Norman Holland, ultrapassando acepções puramente negativas e simplificações do mimetismo corrente, frisou antes de mais nada a identificação manifesta no ato da leitura: "internalizamos as obras literárias e fazemos delas parte dos nossos processos psicológicos do mesmo modo que fazemos da comida parte do nosso sistema digestivo" (HOLLAND, 1975, p. 85). É, de fato, no âmbito da psicanálise que a analogia entre oralidade e identificação encontra seus fundamentos teóricos, permitindo, por sua vez, desdobramentos conceituais que subvertem algumas das noções caras à estética tradicional, como as de distância e de forma. É no âmbito da psicanálise da recepção estética que se torna também possível explicitar um elemento inevitável da comparação do ato de ler ao ato de comer, que é a violência.

Pois comer pressupõe violência. Nesse sentido, por exemplo, ao discutir as complicadíssimas implicações éticas do ato de comer, Kass (1994, p. 13) ressalta seu grande paradoxo, a saber, "que para preservar sua vida e forma, os viventes forçosamente destroem vida e forma". Mesmo sendo deformador e destruidor, o caráter onívoro do ser humano faz dele também um "grande transformador" (KASS, 1994, p. 14), alguém que manipula e altera as formas. De fato, para comer, o ser humano caça, mata, arranca, descasca, corta, trata produtos com fogo, mastiga e, finalmente, digere-os por meio de uma série de processos químicos. Comer é, sem dúvida, 
uma atividade intrinsicamente agressiva, e a própria elaboração de regras, rituais e etiquetas em seu entorno tem como sua função principal "manter fora de cena a violência pressuposta pela refeição que está sendo ingerida” (VISSER, 1998, p. 4).

Com efeito, ao comer algo, fazemos com que um objeto que estava fora de nós e que era diferente de nós, seja trazido para dentro de nós e transformado, química e fisicamente, em uma parte nossa. Trata-se aqui de um processo de interiorização, assimilação e redução, atividades, afinal, também presentes no ato de atribuição de forma ao objeto imaginário a partir do texto de um livro. Foi, aliás, na cultura brasileira que se deu uma das raras e, ao mesmo tempo, mais sinceras revelações da natureza violenta da leitura, subentendida no uso de metáforas alimentares. Tratase, obviamente, da visão irreverente e provocadora da leitura (e da tradução) como uma assimilação unilateral do outro, por meio da "antropofagia" cultural. Essa leitura antropófaga que corresponde a uma tentativa de subversão da relação pós-colonial surge como "reação a todas as indigestões de sabedoria" (ANDRADE, 1924), como um festim canibalesco dirigido pelo gosto e prazer, barbaramente unilateral.

Apesar da agressividade inegável presente em diversos discursos sobre leitura que lançam mão de metáforas alimentares, no âmbito da estética da recepção, que, contudo, acolhe vários procedimentos da negação enquanto elementos importantes da interação fenomenológica entre leitor e texto, poucas vezes se explicitam manifestações de um processo de resistência e, portanto, de uma tensão bastante violenta. A teoria do efeito estético de Iser (1984, p. 290), à diferença da teoria do estranhamento de Victor Chklovski, insiste na importância da imaginação e da memória, afastando-se dessa maneira de toda "consumabilidade" (Konsumierbarkeit) da fruição estética. A própria expressão "consumabilidade", utilizada por Iser para resumir a teoria chklovskiana, através da metáfora alimentar depreciativa, aponta para o esgotamento inerente à experiência do estranhamento.

No entanto, até mesmo na descrição do ato da leitura feita pelo teórico alemão, em decorrência da crescente dificuldade das obras modernas e contemporâneas, como, por exemplo, as de Beckett, surge na interação entre leitor e texto um elemento de forte resistência. De fato, com a intensificação de diversos procedimentos da negação, aumenta o conflito de saberes e normas do qual resulta, por sua vez, uma situação de violência: "a literatura moderna dificulta cada vez mais as negações primárias, responsáveis pela constituição do tema, razão pela qual a formação de representações do leitor se intensifica" (ISER, 1999, p. 186). Evitando metáforas alimentares, Iser (1999, p. 186-187) não deixa, contudo, de descrever a atitude leitora 
através de expressões pejorativas tais como "frustração", "um certo desconforto" e até mesmo "impaciência". Dessa maneira, os atos de representação do leitor revelam-se como não apenas atos de complementar criativamente - de preencher e de combinar -, mas também como enfrentamentos e, enquanto tais, como atos de transformação permeados pela tensão. E, mesmo que o objetivo antropológico da leitura seja para a estética da recepção, antes de mais nada, "estabelecer uma distância quanto a si mesmo e assim descobrir o caráter projetivo de suas representações" (ISER, 1999, p. 187), é justamente na discussão acerca do papel da negação na interação entre texto e leitor que Iser reconhece sua aproximação da psicanálise.

\section{A Leitura E O PALAdAR}

Dentre os nossos cinco sentidos, o paladar não é esteticamente o mais apreciado, sendo frequentemente interpretado como, em oposição à visão, indiferente às formas. Apenas o olfato, do qual o paladar intimamente depende, precede-o na escala depreciadora dos sentidos considerados como puramente químicos e animais. Assim, refletir sobre as metáforas alimentares da leitura permite também questionar as limitações da estética, sobretudo naquilo que tange a suas promessas irrealizadas de se constituir em uma teoria do conhecimento sensível. Pois dos cinco sentidos, apenas dois, a visão e a audição, são plenamente levados a sério. O tato, é verdade, adquiriu um teor conceitual considerável do âmbito da fenomenologia da percepção. O paladar e olfato, mesmo tendo se mostrado bastante atrativos como componentes das poéticas da sinestesia a partir do século XIX, apenas recentemente começaram a suscitar discussões teóricas, sobretudo no âmbito dos estudos do gênero.

Ao lado do olfato, o paladar é, sem dúvida, um dos nossos sentidos menos treinados e menos educados, suas experiências, por muitos vivenciadas como indizíveis e confusas, dificilmente sendo traduzidas em discurso. Há quase dois séculos, em seu livro revolucionário A fisiologia do gosto, publicado em 1825, Brillat-Savarin (1995, p. 45) observava:

Ora, como até hoje não se apresentou nenhuma circunstância em que um sabor devesse ser apreciado com rigorosa exatidão, tivemos de nos contentar com um pequeno número de expressões gerais, tais como doce, açucarado, ácido, amargo e outras semelhantes, que se exprimem, em última análise, pelas duas seguintes: agradável ou desagradável ao gosto [...]. 
Foi o mesmo Brillat-Savarin um dos primeiros a sugerir a possibilidade e um esboço de uma análise formal dos sabores, ao dizer: "no mesmo ato de deglutinação podemos experimentar sucessivamente uma segunda ou até uma terceira sensação, que vão se enfraquecendo gradualmente, e que designamos pelas palavras ressaibo, perfume ou fragrância" (BRILLAT-SAVARIN, 1995, p. 49). É, contudo, impensável deixarmos de levar o paladar a sério na literatura depois da inesquecível e, em muitos sentidos, inaugural Petite Madeleine mergulhada no chá, cujo sabor deflagrou (não apenas no protagonista do Em busca do tempo perdido, mas também em seu leitor) um desdobramento de diversas temporalidades, em um passe de magia, abolindo as sensações de ser "medíocre, contingente e mortal" (PROUST, 1988, p. 44). Poucos, no entanto, sabem "descascar a sucessão de sensações" (BARBERY, 2009, p. 19), como o faz, por exemplo, o gourmet, protagonista da recente narrativa de Muriel Barbery, que, ao contrário do narrador proustiano a quem o sabor se revelou subitamente, procura concretizar, nas últimas horas de sua vida, a lembrança perdida de um sabor excepcional.

A narrativa de Barbery, além de ser um aprofundamento da experiência do paladar proustiana, é um impressionante exercício discursivo que (tal como fazia o Perfume, de Patrick Süskind, com os cheiros) retira do silêncio as características formais dos sabores. Poucos, de fato, conseguem apreciar as qualidades formais da comida entrevistas por Brillat-Savarin, como, por exemplo, o contraste "entre a aspereza de uma carne simples e poderosa e a ternura cúmplice de uma guloseima supérflua" (BARBERY, 2009, p. 24); as combinações paradoxais de um sabor "sutil e expansivo ao mesmo tempo" (BARBERY, 2009, p. 35); as nuanças reveladas pela fruição do próprio movimento da boca, que permite "a nova mudança do quadro, pois o palato acaba de esposar a espuma alveolada libertada de sua canga e o trabalho dos maxilares pode começar" (BARBERY, 2009, p. 68); ou até mesmo o excesso: "uma deflagração de pimenta e de elementos furiosos que detona de repente na boca; os órgãos já não existem, não há mais palato, nem bochechas, nem mucosas" (BARBERY, 2009, p. 101).

Era preciso esperar as discussões contemporâneas a respeito da relação entre a estética e o gênero, para que se considerasse a inclusão do paladar entre os sentidos esteticamente relevantes. No âmbito da estética feminista, Carolyn Korsmeyer frisa, por exemplo, que a marginalização da comida e do paladar no pensamento filosófico ocidental é muito reveladora quanto aos sentidos atribuídos ao gosto estético, à distância estética e à delimitação do campo da arte. Além de se mostrar como 
dominada pelas oposições hierárquicas entre razão e emoção, mente e corpo e entre abstração e particularidade, a estética filosófica tradicional revela-se também como regida pela oposição entre o masculino e o feminino. A autora nota não sem ironia:

É óbvio que na maioria das culturas são as mulheres que preparam comida. O que é menos óbvio e mais interessante são as ideias matizadas genericamente do corpo, da comida, dos prazeres gustativos e o próprio sentido do gosto que envolve conceitos do valor estético e das belas artes. (KORSMEYER, 2004, p. 85).

Na teoria feminista de Hélène Cixous, subversiva em relação à hierarquia tradicional dos sentidos, o conhecimento se dá a partir do regime estético. E ele começa justamente naquele dos cinco sentidos que está mais intimamente relacionado ao corpo, surgindo primeiramente pela boca e pelo paladar: "Foi nos contado que o conhecimento começava pela boca, pela descoberta do gosto de algo. Conhecimento e gosto vêm juntos" (CIXOUS, 1989, p. 138). Em um sentido parecido, Cixous relata também a experiência de leitura de textos de Clarice Lispector como um "influxo de laranja” (CIXOUS, 1989, p. 17) que se espalha pelo corpo todo. E entre muitos sentidos que a palavra "laranja" ("orange") sugere, o de um sabor e um saber de fruta tropical é inevitável: "Sinto vitalmente a necessidade de compartilhar o sabor acidulado e calmante da escrita-presente, o gosto terno, discreto, embriagante daquela que escreve na origem do instante, antes do tempo, do ladinho da eternidade" (CIXOUS, 1989, p. 65). Longe de ser desprezado enquanto um sentido baixo, animal e irrelevante do ponto de vista da aquisição do conhecimento, o paladar se torna a fonte de todos os prazeres e de todos os saberes: "o verdadeiro saber é um saborear" (CIXOUS, 1982, p. 12).

\section{A leitura e o corpo do texto}

Talvez a presença das metáforas alimentares da leitura aponte simplesmente para o fato de que o domínio do estético é um espaço privilegiado de fusão entre o somático e o psíquico. Que a leitura mantém um parentesco com o ato de comer, sabem, contudo, não apenas autores de narrativas de consumo, nos quais leitores gulosos fazem seus piqueniques e seus festins escapistas. Até mesmo o poeta hermético Mallarmé chegou a aproximar a carne e os livros em um único verso espetacular no início da "Brisa marinha": "A carne é triste, sim, e eu li todos os livros" 
(CAMPOS, 1991, p. 45). E ainda fez rimar "livres" (livros) com "ivres" (bêbados), sugerindo dessa maneira uma impressionante confusão entre a leitura e a embriaguez: "La chair est triste, hélas! et j'ai lu tous les livres. / Fuir! Là-bas fuir! Je sens que les oiseaux sont ivres" (CAMPOS, 1991, p. 44). É justamente desse festim de carne e de livros que o sujeito poético mallarméano deseja escapulir. "Nem minha carne foi triste nem tampouco eu li todos os livros" (OROZCO, 2009, p. 31), responde Olga Orozco um século mais tarde ao verso da "Brisa marinha". No início de um dos seus últimos textos, publicados postumamente, a poeta argentina reescreve audaciosamente a cena da escrita mallarméana enraizada no naufrágio, no tédio, enfim, na saciedade. Contudo, na reencenação feminina de Orozco não há nem tédio, nem evasão, nem saciedade, e os versos mallarméanos "Fugir! Fugir! Sinto que os pássaros são livres" (CAMPOS, 1991, p. 45) encontram um forte contraponto dialógico: "De quem fugir? E aonde? E por quê?" (OROZCO, 2009, p. 32). É também curioso que a leitura do exatamente mesmo verso tenha sido relatada por Hélène Cixous:

Lembro-me, aos 12-13 anos li a frase seguinte: "A carne é triste, sim, e eu li todos os livros". Fiquei abalada por uma surpresa misturada de desprezo e de nojo. Como se uma tumba tivesse falado. Que mentira! E para além, que verdade: pois a carne é livro. Uma carne "lida", acabada? Um livro-carcaça? Fedor e falsidade. A carne é escrita e a escrita nunca fica lida: ela é sempre a ler, a estudar, a buscar, a inventar. (CIXOUS, 1977, p. 30-31)

As releituras poéticas do verso mallarméano por Cixous e Orozco permitem observar uma mudança importante quanto ao valor sugerido pelas metáforas alimentares da leitura. Elas deixam, de fato, de apontar exclusivamente para características negativas. Tendo como sua pré-história na estética tradicional a teoria do "gosto", o uso das metáforas alimentares da leitura intensificou-se nas últimas décadas graças a uma fecunda exploração teórico-poética da comparação entre corpo/carne e texto. E trata-se dessa vez de um corpo-texto vivo, dinâmico e cheio de desejo. Pois, mesmo que tenha existido há muito a denominação "corpus" para designar um conjunto de textos sobre um determinado assunto, essa expressão, remetendo à ideia do acabamento, sugeria também as de imobilidade e de fechamento, senão de morte.

Ausentes na estética da recepção de cunho alemão, que, ao deixar à margem emoções e, sobretudo, ao evitar cuidadosamente todos os eventuais envolvimentos somáticos do leitor, procura afirmar a distância estética como articuladora da fruição e, assim, frisar antes de mais nada o teor cognitivo da experiência da recepção, as 
metáforas alimentares da leitura manifestam-se com bastante frequência na reflexão teórica pós-estruturalista. Elas se tornam bastante recorrentes, e sua acepção passa a ser positiva em todas aquelas teorias recentes que lançam mão de metáforas do corpo e/ou da carne para refletir sobre o texto literário. Longe de se reduzirem à descrição depreciativa da leitura como consumo ou da literatura de consumo, as expressões que comparam as atividades de ler e de comer correspondem, de fato, a intenções teóricas que reivindicam a relação íntima entre o texto e o corpo.

Extremamente irreverente enquanto um esboço de uma estética inteiramente baseada no "prazer do consumidor", O prazer do texto, de Roland Barthes, publicado em 1973, é um dos primeiros e até hoje um dos mais marcantes exemplos de uma tal reivindicação. Ao suportar sem vergonha a contradição, a confusão, a multiplicidade e a incompletude, o leitor bartheano entrega-se à "jouissance" (usufruto/gozo/ fruição), que não nega o prazer físico como seu componente relevante. $O$ próprio texto é um anagrama do nosso "corpo erótico" (BARTHES, 2013, p. 24), e o início da relação prazerosa com ele se dá através de expressões que remetem à amamentação: "espuma de linguagem", "criança de peito", "fonemas lácteos", "gastrosofia" (BARTHES, 2013, p. 9). Além disso, existe um ritmo de ler comparável ao ritmo de comer e, nesse sentido, Barthes diferencia duas leituras: uma rápida e rapidamente saciada, que engole o texto, procurando por articulações mais nutrientes, as da intriga, e pela solução-satisfação da anedota; a outra, que longamente mastiga, saboreia e tende a prestar atenção aos elementos formais, tentando "não devorar, não engolir, mas pastar, aparar com minúcia” (BARTHES, 2013, p. 19). Os alimentos bem-amados surgem no texto bartheano na flor das palavras frequentemente repetidas e também em suas traduções: desfrutar, deleite. Ao distinguir entre o texto que "enche" e o texto de fruição que aguça o apetite e deixa insatisfeito, Barthes sugere que esse segundo é incompatível com o estado de saciedade, pois não raramente apenas estimula a fome do leitor.

Na mesma década dos anos 70, ao afirmar a prática da "écriture féminine" e a vitalidade de sua relação com o corpo, Cixous (1977, p. 19) numerosas vezes ressalta o papel explicitamente alimentício de livros e de palavras: "Os textos, eu os comia, eu os chupava, os mamava, os beijava. Sou a filha inumerável de sua multidão". A leitura, solidária no texto cixousiano não apenas da diversidade de linguagens, mas também da multiplicidade de línguas, chega a ser descrita como uma alternativa da comida, uma opção pacífica que rejeita a agressividade intrínseca ao gesto de comer: "Cresci no leite das palavras. As línguas me alimentaram. Detestava comer 
o que tinha no prato. Desgraçadas cenouras, sopas ruins, agressividade de garfos e facas." (CIXOUS, 1977, p. 27).

Lembremos que essa alternativa entre ler e comer já havia sido sugerida no início do ensaio "Sobre a leitura", de Proust. As refeições que marcam o ritmo do dia da criança são chamadas de "obstáculos vulgares" (PROUST, 1993, p. 9) que atrapalham a continuidade do mergulho no livro. A necessidade de comer - por exemplo, aquele "lanchinho que haviam nos preparado e que largamos do lado no banco sem tocar" (PROUST, 1993, p. 9) - é interpretada como um empecilho da atividade desejada. As palavras mais fatais lembradas daquele tempo de leituras embriagantes são aquelas que interrompem a atividade de ler com uma injunção à refeição: "Vamos, feche o livro, está na hora do almoço" (PROUST, 1993, p. 12).

Qualquer linguagem pressupõe, de fato, "uma desterritorialização da boca, da língua e dos dentes" (DELEUZE, 1977, p. 30), que encontram sua primeira territorialidade nos alimentos. Para Cixous, como para o Kafka de Deleuze e Guattari, não apenas escrever, mas também ler coteja por vezes o domínio de doenças alimentares, aproximando-se um tanto perversamente do seu contrário, que é jejuar. Se Kafka expõe sua dor linguístico-alimentar na figura do artista da fome, Beckett há de levar sua escassez mais longe ainda, encenando em seus textos linguisticamente dilacerados atos tão paradoxais quanto a perturbadora prática de "chupar as pedras" (BECKETT, 2014, p. 101-108). Parece que, mesmo se as palavras, as línguas e as leituras possam substituir alimentos, tornando-se nutrientes, quando desterritorializadas, nunca permitem saciedade, nunca levam à plenitude das línguas próprias, plenas, territoriais e fartas. Apenas a linguagem poética apresenta-se por vezes capaz de recuperar algo da genuína inocência alimentícia, algo daquele "leite do amor" e daquele "mel do inconsciente" que afinal "correm em todas as línguas" (CIXOUS, 1977, p. 28). Envolvida em ambivalências das línguas desterritorializadas, na teoria poética de Cixous a leitura é apresentada sobretudo como uma atividade alimentícia capaz de nutrir e de fazer crescer a escrita feminina, uma amamentação que assegura uma vida e uma emergência. $\mathrm{O}$ ato de escrever surge como um gesto de alimentação recíproca, o gesto de "alimentar minha própria mãe. Dar-lhe de mamar por minha vez" (CIXOUS, 1977, p. 20). Essa natureza nutriente da leitura estende-se, aliás, também a propriedades que os livros possuem de manter a vida, como "corpos de sangue e de papel; suas letras de carne e de lágrimas; que põem fim ao fim" (CIXOUS, 1977, p. 20). 
As metáforas alimentares da leitura não são as mais praticadas. Parece-me que imagens e expressões que possuem o maior alcance no discurso crítico e teórico sobre a leitura remetem, antes, a metáforas espaciais e, com isso, a experiências táteis. "Espaço íntimo", "universo do texto", "viagem”, "mundo representado", apenas para citarmos as expressões mais conhecidas, têm uma longa tradição, por exemplo, nas ricas metáforas náuticas da hermenêutica. Essa tradição foi revisitada no século XX, no âmbito da fenomenologia da leitura e da estética da recepção com suas propostas figurativas do "leitor viajante" que transita entre mundos e dos "lugares vazios" que criativamente atrapalham seus percursos.

Comparadas com as metáforas espaciais, as expressões alimentares surgem como excessivas, senão caricaturais. Mas a falta de moderação é, de fato, seu cerne. Se a popularização da leitura solitária e silenciosa a partir do século XVIII, acompanhada da exclusão do corpo, tão presente na leitura pública e em voz alta, insistiu no silêncio, na imobilidade e na interiorização abstrata como elementos principais do ato de ler, as metáforas alimentares logo desmentiram a ausência das atividades corporais e até mesmo viscerais do leitor. Extremamente versátil, seu uso pode ser depreciador, visando à crítica dos excessos leitores no que tange tanto à quantidade das leituras quanto a sua qualidade, ou apreciativo, valorizando os envolvimentos emocionais e somáticos dos leitores com os textos-corpos. Mas, mesmo enquanto traduções afirmativas desse corpo a corpo do leitor com o texto, elas fazem entrever diversas patologias linguístico-alimentares. Seja como for, as metáforas alimentares da leitura, mesmo quando usadas no sentido ambivalente ou até pejorativo, revelam seu forte potencial crítico quanto aos limites do regime estético.

\section{REFERÊNCIAS}

ANDRADE, Oswald de. Manifesto antropófago e Manifesto de poesia pau-brasil. Disponível em: <http://www.ufrgs.br/cdrom/oandrade/oandrade.pdf>. Último acesso em: 09 maio 2015.

BARBERY, Muriel. A morte do gourmet. Trad. Rosa F. d'Aguiar. São Paulo: Companhia das Letras, 2009. BARTHES, Roland. O prazer do texto. Trad. J. Guinsburg. São Paulo: Perspectiva, 2013.

BECKETT, Samuel. Molloy. Trad. Ana Helena Souza. São Paulo: Globo, 2014.

BRILLAT-SAVARIN, Jean-Anthelme. A fisiologia do gosto. Trad. Paulo Neves. São Paulo: Companhia das Letras, 1995.

CAMPOS, Augusto de et al. Mallarmé. São Paulo: Perspectiva, 1991.

CIXOUS, Hélène et al. La venue à l'écriture. Paris: Union Générale d'Éditions, 1977.

CIXOUS, Hélène. Limonade tout était si infini. Paris: Des femmes, 1982. 
CIXOUS, Hélène. L'heure de Clarice Lispector précédé de Vivre l'orange. Paris: Des femmes, 1989. DELEUZE, Gilles; GUATTARI, Félix. Kafka: por uma literatura menor. Trad. Júlio C. Guimarães. Rio de Janeiro: Imago, 1977.

HOLLAND, Norman N. Poems in persons. An introduction to the psychoanalysis of literature. New York: The Norton Library, 1975.

HRABAL, Bohumil. Eu servi o rei da Inglaterra. Trad. Manoel P. Ferreira. São Paulo: Companhia das Letras, 2002.

ISER, Wolfgang. Der Akt des Lesens. Theorie ästhetischer Wirkung. Stuttgart: Fink, 1984.

ISER, Wolfgang. O ato da leitura. Uma teoria do efeito estético. Trad. Johannes Kretschmer. São Paulo: Editora 34, 1999. v. 2.

KASS, Leon R. The hungry soul. Eating and the perfecting of our nature. New York: The Free Press, 1994. KORSMEYER, Carolyn. Gender and aesthetics. An introduction. Nova York: Routledge, 2004.

OROZCO, Olga. Últimos poemas. Buenos Aires: Bruguera, 2009.

PETIT, Michèle. Leituras: do espaço íntimo ao espaço público. Trad. Celina O. de Souza. São Paulo:

Editora 34, 2013.

PROUST, Marcel. Du côté de chez Swann. Paris: Gallimard, 1988.

PROUST, Marcel. Sur la lecture. Paris: Actes Sud, 1993.

VISSER, Margaret. O ritual do jantar. As origens, evolução, excentricidades e significado das boas maneiras à mesa. Trad. Sônia Coutinho. Rio de Janeiro: Campus, 1998.

WITTMANN, Reinhard. Une révolution de la lecture à la fin du XVIIIe siècle?. In: CAVALLO, Guglielmo; CHARTIER, Roger (Org.). Histoire de la lecture dans le monde occidental. Paris: Seuil, 2001. p. 355-391.

\section{SOBRE A AUTORA}

Olga Donata Guerizoli Kempinska tem graduação e mestrado em Filologia Românica pela Uniwersytet Jagiellonski, de Cracóvia, e doutorado em História Social da Cultura pela PUC-Rio. É professora de Teoria da Literatura do Departamento de Ciências da Linguagem da Universidade Federal Fluminense. Publicou, em 2011, o livro Mallarmé e Cézanne: obras em crise, pela Editora Nau. E-mail: olgagkem@gmail.com

Recebido em 18 de maio de 2015 e aprovado em 23 de novembro de 2015. 